\title{
Characterization of low-density polyethylene reference material for melt flow rate by collaboration of NIS and a network of competent laboratories
}

\author{
Hesham Moustafa $\oplus^{1 *}$, Ibrahim F. Tahoun $\oplus^{2}$, Ahmed I. Abou-Kandil \\ and Nabila A. Darwish ${ }^{1} 1$ \\ ${ }^{I}$ Department of Polymer Metrology \& Technology, National Institute of Standards (NIS), Tersa Street, \\ El Haram, P.O Box 136, Giza 12211, Giza, Egypt \\ ${ }^{2}$ Reference Materials laboratory, National Institute of Standards (NIS), Tersa Street, El Haram, P.O
}

Box 136, Giza 12211, Giza, Egypt

(Received July 25, 2021; September 11, 2021; Accepted September 30, 2021)

\begin{abstract}
The growth rate of plastic manufacturing all over the world and in the middle east as oil producing countries increased the rate of thermoplastics production and the needs of reference materials (RMs) for use in performance evaluation of measuring instruments and ensuring validity of measurement results. This article was focused on the preparation of RM based melt mass-flow rate from low-density polyethylene (LDPE) according to ISO 1133-1 standard. The characterization was evaluated from around 10\% of prepared units, then the samples were distributed to a network of collaborating laboratories in order to ensure the validity of the RM production process. The value of melt mass-flow rate of LDPE was determined to be $19.51 \mathrm{~g} / 10 \mathrm{~min}$ under a temperature of $190^{\circ} \mathrm{C}$ and a load of $2.16 \mathrm{~kg}$ with expanded uncertainty 0.38 at $95 \%$ confidence level. The obtained values were confirmed from the data reported by the network of collaborating laboratories.
\end{abstract}

Keywords: Reference material; melt mass-flow rate; LDPE; ISO 1133-1; homogeneity and stability; collaborative study. (C) 2021 ACG Publications. All rights reserved.

\section{Introduction}

Most plastic materials are subjected to various tests but only few of them are essential to check the quality of the final product. Among them, melt mass-flow rate (MFR) which is an important property used to characterize plastics during polymer processing, in addition to the density. MFR is defined as: the rate of extrusion of a molten resin through a die of specified length and diameter under prescribed conditions of temperature, load and piston position in the cylinder of an extrusion plastometer, the rate being determined as the mass extruded over a specified time [1-5]. Additionally, MFR plays a pivotal role for controlling the quality of thermoplastic products. For instance, it can effectively differentiate if the

\footnotetext{
* Corresponding author: E-Mail: hesham.moustafa21@gmail.com Phone: +201 01734580 0; Fax: 002023386745
} 
plastic is virgin, recycled, amorphous, crystalline, filled or unfilled with a certain type of filler. Moreover, MFR information could be an indication of the molecular weight $(\mathrm{Mw})$ of the material $[6,7]$.

Under specified conditions of temperature and load, procedure (A) in ISO 1133-1 [8] standard is used for unfilled thermoplastics. This measurement is also applicable to thermoplastics for which the rheological behavior is affected during the measurement by phenomena such as hydrolysis (chain scission), condensation and crosslinking, but only if the effect is limited in extent and only if the repeatability and reproducibility are within an acceptable range. For materials which show high variation in rheological behavior during testing, ISO 1133-2 is not appropriate and ISO 1133-1 applies. On the other hand, melt volume-flow rate (MVR) is particularly useful when comparing materials of different filler content and when comparing filled with unfilled or blends with other thermoplastics. The MFR can be determined from MVR measurements, or vice versa, provided the melt density at the test temperature is known.

Now-a-days, the application of certified reference materials (CRMs) in analytical chemistry for quality control purposes is well recognized and recommended by a wide range of organizations. The use of CRM encourages the quality assurance and quality control in analytical laboratories [9]. There are commercially available CRMs and reference materials (RMs), however, for certain matrix types, CRMs might not be available at all, or the range of concentrations and/or analytes needed might not be certified. In many of the analytical laboratories in developing countries lack of financial resources restrict the comprehensive use of available CRMs that are largely prepared and commercialized in western countries. The concept of in-house RMs or quality control materials (QCMs) is advocated to supplement (not substitute) the use of CRMs for quality control purposes. The concept of using QCMs is widely applicable to: advanced laboratories with CRMs with validated analytical techniques available, laboratories with less experience and facilities, and where labile compounds and unstable matrices are involved. Each case considers different approaches to overcome the lack of appropriate CRMs and advise on the preparation of QCMs, which might fit the particular purpose. For these reasons, this publication is intended to assist analytical chemists in their efforts to maintain good quality results and provide them with a tool to overcome situations where QA/QC could not be easily implemented. The report is a contribution to promote quality system implementation and finally encourage testing laboratories in Egypt or in its neighboring countries to prepare themselves for formal accreditation.

Polyolefins including low-density polyethylene (LDPE), high-density polyethylene, and polypropylene $[10,11]$ attracted attention of scientists because of their use in a wide spectrum of engineering applications such as automobile, electrical cables, healthcare purposes, food packaging [12], and other industrial applications. Their availability from simple olefins monomer, easy processing with respect to other polymers, excellent mechanical, molding and recycling properties, make them amongst the highest used commodity polymers. Polyolefins are highly stable to the environmental effects, have long life, and can take several decades for the degradation $[13,14]$. Furthermore, their resistance to ultraviolet irradiation and hydrophobicity nature could be a promising to increase their resistance to microorganism's activity. They have also been used for UV shielding amongst many other engineering applications [15-17]. With regard to the previous literature, the grafting of the branched LDPE by acrylic acid (LDPE-g-AAc) using melt-blending has been performed to create a new component with different properties such as molecular weight, crystallinity, melting point, and thermal stability $[18,19]$. Measuring the melt flow rate is essential for defining the different grades of the LDPE with different MFR ranging from 0.25 to $36 \mathrm{~g} / 10 \mathrm{~min}$ and their suitability for use in certain applications and well as determining its filler content. Practically speaking, there are hundreds of grades of polyethylene and law density polyethylene that differ mainly in their densities. The slight differences in the polymerization procedure, the initiators used and the polymerization temperature would result in large differences in MFR values. This is turn will affect the processability of the polyethylene and consequently the application of its intended use. In this respect, the MFR results normally based on the test method used. For instance, NIST prepared a Reference Material (SRM- 1473b) for LDPE resin based on ASTM 1238 standard. ISO 11331 was not used before in certification of reference materials. Our reference material was prepared according to ISO 1133-1 because most companies and laboratories in Egypt and countries of the MENA region use this standard for quality control and interlaboratory comparison. Work by Chui et al. used 
interlaboratory programs [20] are statistical tools used to compare the results of different laboratories for the same material, to determine the precision of a standard method of measurement, to assess laboratory performance and to attribute values to materials. It is incorrect to assess laboratory performances based on samples of unknown homogeneity and quality.

Herein, we describe a method for evaluating the homogeneity and stability of thermoplastic LDPE and also describe characterization and value assignment according to ISO 17034. Additionally, the results that were obtained from the collaborative trails study were used to affirm the assigned value for MFR property and uncertainty of measurements for the LDPE samples under investigation.

\section{Materials and Methods}

\subsection{Planning}

The preparation and characterization of LDPE reference material comprises the complete process from selection of material to after-sales service as described in Figure S1 (see supporting information). It includes the steps of processing of material, homogeneity testing, and stability testing, characterization and value assignment according to ISO 17034. The study focuses on characterization of the reference material using ISO 1133, the characterization approach was based on NIS metrologically valid procedure and confirmation of value by a network of competent laboratories. In order to ensure best practice, the Polymer Metrology and Technology Laboratory (PMTL) and the Reference Materials Laboratory (RML) at NIS, Egypt, collaborated in order to produce a CRM for MFR. It can be used to enhance the quality control and quality assurance of MFR measurements in different industries and laboratories in Egypt and around the world with an affordable price especially for developing countries. The experimental design is summarized in Figure 1 and shows a stepwise procedure that was followed according to ISO 17034 in order to produce the CRM for MFR of LDPE.

\subsection{Materials Processing and Packaging}

Five kilograms of low-density polyethylene (LDPE) with density of $0.9130 \mathrm{~g} / \mathrm{cm}^{3}$ were obtained from Sidi Kerir Petrochemicals Company (SIDPEC), Alexandria-Egypt. They were sampled and mixed well to enhance homogeneity and packed into $50 \mathrm{~g}$ units to yield a batch of approximately 100 units. The units were numbered from 1 to 100 according to filling sequence, divided into 10 groups (G1 to G10), each group includes 10 units as illustrated in Figure 1. The groups were stored in a dry and clean area for further investigations.

\subsection{Equipment and Measurement Procedure}

The homogeneity and stability studies were evaluated at in PMTL and RML at NIS, using Zwick Extrusion Plastometer (Model 4100, Germany) (see Figure S2 in supporting information). The melt flow rate of LDPE was determined according to International standard ISO 1133-1:2011 (Procedure A) [8], the same procedure was used by all collaborative laboratories. Instructions were prepared by PMTL-NIS for all laboratories regarding measurement time frame, metrological traceability, test method and number of measurements per each unit. The measurement procedure based on using of $2.16 \mathrm{~kg}$ load, $190{ }^{\circ} \mathrm{C}$ cylinder temperature, $30 \mathrm{~s}$ cut-off time interval between extruded specimens and weight of extruded filaments using highly sensitive balance. In which the instrument was allowed to stabilize for at least 20 min and the preheat temperature calibrated prior to the sample insertion into the cylinder using a thermocouple sensor with a variation approximately $\pm 0.1^{\circ} \mathrm{C}$. All equipment including balance (Mettler Toledo, model MS204S/01, Switzerland), Zwick Extrusion Plastometer and thermocouple were traceable to SI units. The MFR values were expressed as $\mathrm{g} / 10 \mathrm{~min}$. 
Moustafa et al., J. Chem.Metrol. 15:2 (2021) 102-112

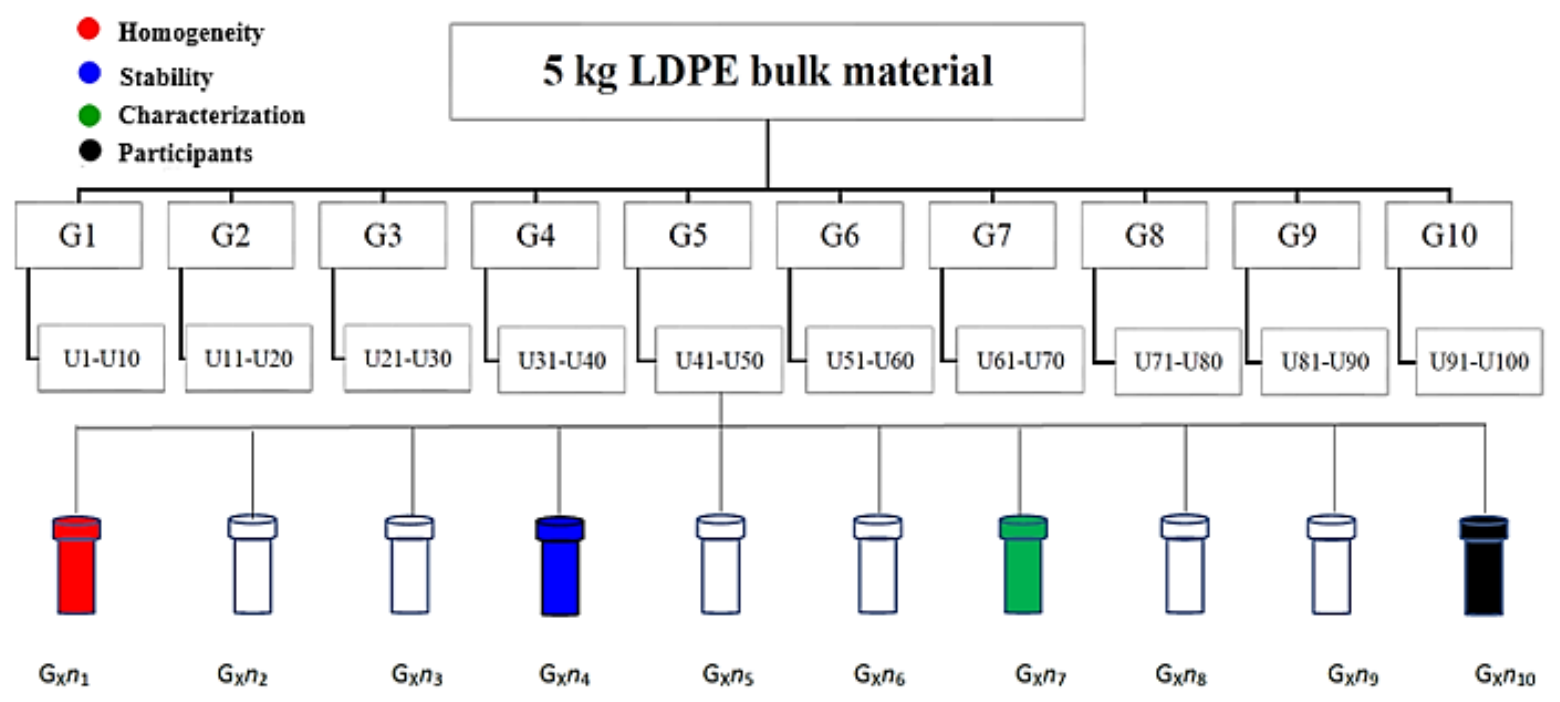

Figure 1. Stratified random selection diagram used in the sample preparation for the homogeneity and stability assessments, as well as participant laboratories

\subsection{Test of Homogeneity}

The homogeneity study was designed to quantify any differences between unit heterogeneity of the prepared material. Systematic sampling approach was used to select ten units from the whole batch. Three sub-samples from each unit were measured three times each under repeatability conditions. All samples were analyzed randomly to ensure that the order of measurements did not correspond to the filling sequence of the bottles. Data were analyzed by ANOVA to check homogeneity of samples and estimation of uncertainty due to heterogeneity effect.

\subsection{Test of Stability}

A classical stability study was applied $[21,22]$ to evaluate stability of material under normal laboratory conditions. Ten units were selected from the batch, stored at ambient conditions $\left(22 \pm 3{ }^{\circ} \mathrm{C}\right)$ and one unit was analyzed in triplicates at two months' time interval for 18 months. The data were screened for outliers using the Grubbs test. Linear regression analysis as a function of time was performed and slopes were tested for significance using a $t$-test $[21,22]$.

\section{Results and Discussion}

\subsection{Homogeneity Assessment}

The results of the homogeneity study illustrated in Figure 2 were analyzed according to ISO Guide 35:2017 and uncertainty of the material was estimated and combined with other sources to estimate expanded uncertainty [23-27]. The uncertainty $u_{\mathrm{bb}}$ was estimated from the difference between the total variability and the within bottle variability using the following equation [21]:

$$
u_{\mathrm{bb}}=\sqrt{M S_{\text {within }} / n} \cdot \sqrt[4]{2 / N(n-1)}
$$

Where $M S_{\text {within }}$ represents within groups mean squares, $\mathrm{n}$ is the number of replicate sub-samples per bottle and $\mathrm{N}$ is the number of bottles selected for homogeneity study. 
Characterization of low-density polyethylene reference material

On the basis of results of one-factorial analysis of variance (ANOVA), the $M S_{\text {between }}$ are smaller than $M S_{\text {within }}$ which indicates that, the homogeneity of the material is better than repeatability of the measurement method and this is normal for melt flow testing. The values of $M S_{\text {between }}, M S_{\text {within, }} \mathrm{P}$-value, F-value are $0.0069,0.0531,0.998$ and 0.1298 , respectively. The estimated value of material heterogeneity is 0.089 ; this value is incorporated in the expanded uncertainty of calculated reference value.

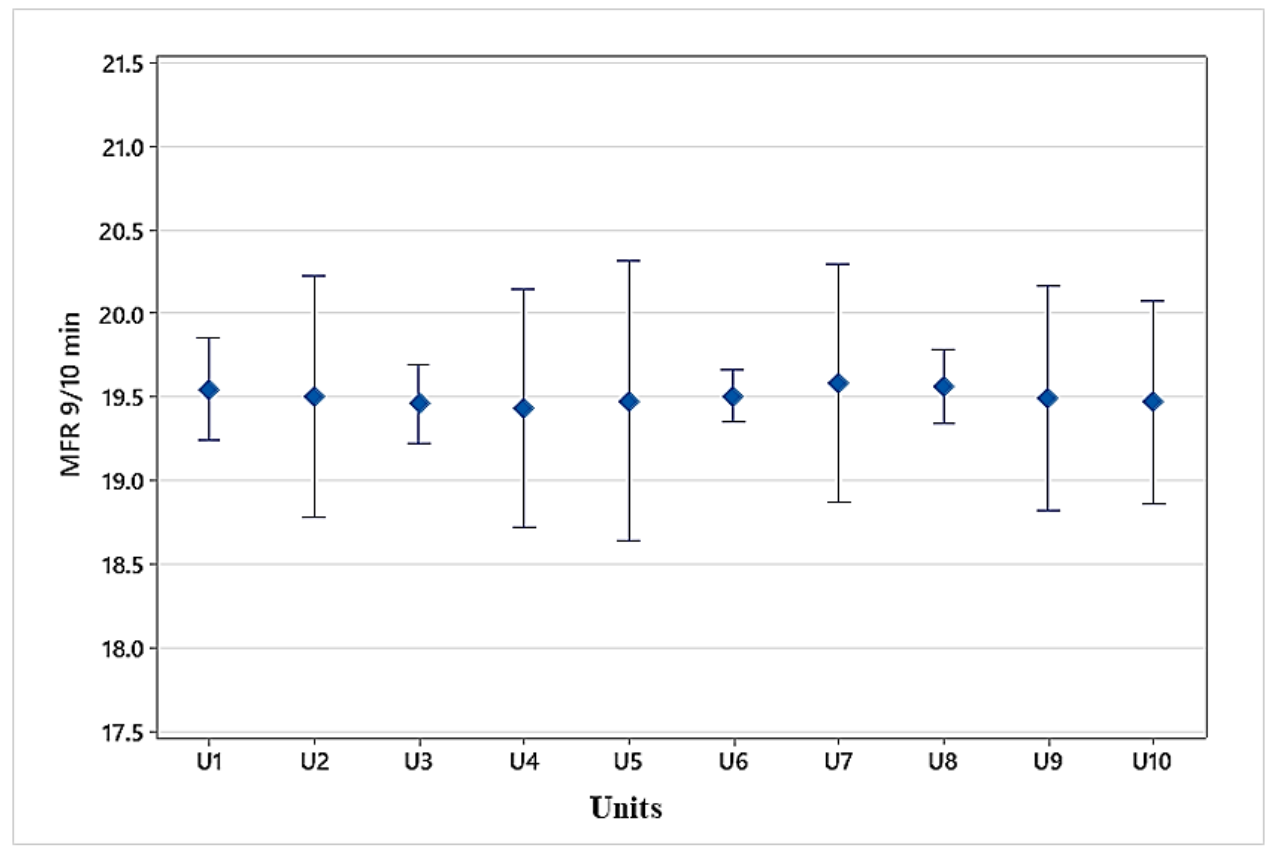

Figure 2. Graphical representation of homogeneity evaluation results

\subsection{Stability Assessment and Assigning Material Shelf Life}

Classical stability study approach was applied to investigate stability of LDPE at ambient conditions used for storage and transportation $[22,28]$. Stability study was performed over a period of 18 months at two months intervals. Ten units were stored in laboratory area and after the predetermined storage periods, the units were measured in triplicates. Stability data were screened for stragglers and outliers by applying Grubbs' test at confidence levels of $95 \%$ and $99 \%$, respectively. After treatment of outliers, data was plotted as a function of time as illustrated in Figure 3 and the regression line was checked using a $t$-test at $95 \%$ confidence interval $(\alpha=0.05)$ for significant trends possibly indicating change in the melt flow value. The values of slope and its error are -0.0019 and 0.004168 , respectively. On the basis of the results, the storage of prepared material is recommended at laboratory normal temperature $\left(22 \pm 3{ }^{\circ} \mathrm{C}\right)$. The uncertainty due to material instability estimated from regression line slope is incorporated in the combined uncertainty of the assigned value. The prediction of the material shelf life was based on standard uncertainty due to long term stability and uncertainty allowance due to instability was evaluated according to the Equation 2 [29-31].

$$
u_{l t s}=Y_{0} X u_{s t}
$$

Where, $Y_{0}$ is initial value, $X$ is time point and $u_{\mathrm{st}}$ is standard uncertainty due to long term stability. 
Moustafa et al., J. Chem.Metrol. 15:2 (2021) 102-112

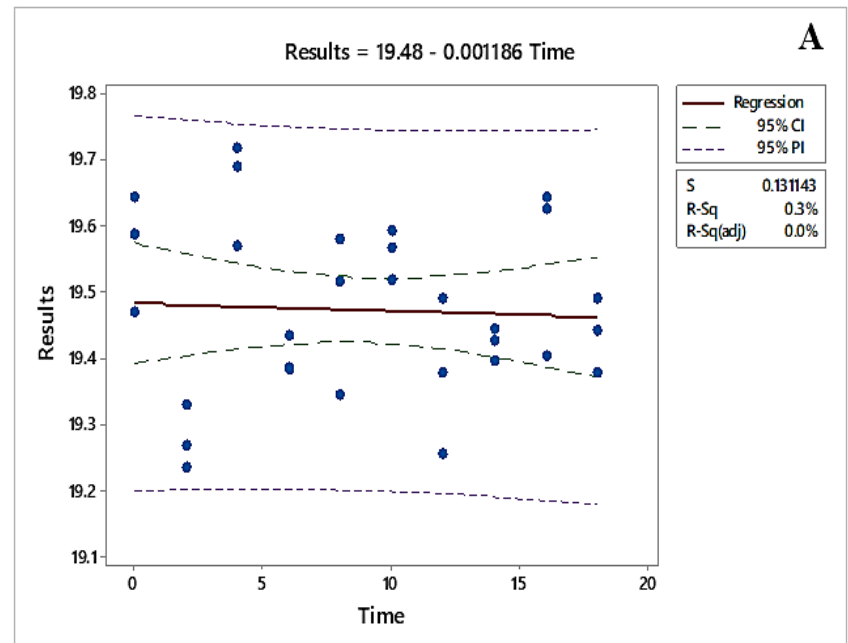

A

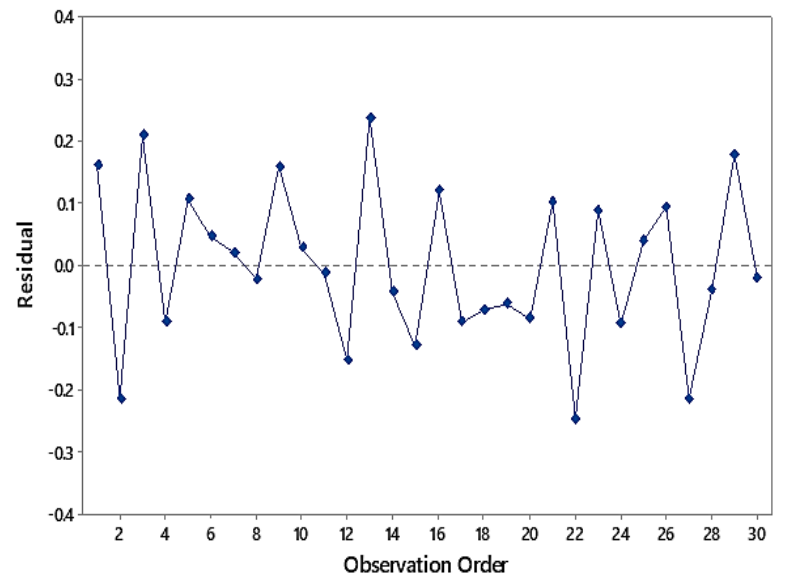

Figure 3. A) Linear regression plots for long-term stability study during 18 months of storage at ambient temperature for reference material, B) Graphical representation of testing order.

The mean response slope illustrated in Figure 3 is not significantly different from zero which indicates a sufficient stability of the material stored at an ambient temperature. Therefore, an expiry date of two years was established within estimated uncertainty (0.16). Stability testing will be continued by further measurements over the period of availability of the material to maintain confidence in the reference value.

\subsection{Characterization of LDPE Reference Material}

Characterization of LDPE reference material was based on ISO 1133-1. The material was measured by accredited PMTL-NIS using calibrated equipment and traceable to SI units, the measurement procedure based on using of $2.16 \mathrm{~kg}$ load, $190{ }^{\circ} \mathrm{C}$ cylinder temperature, and $30 \mathrm{~s}$ cut-off time interval. Ten units were measured in ten different days by different analysts to avoid any systematic errors. The results of NIS characterization are illustrated in Table 1.

Table 1. PMTL-NIS measurement results

\begin{tabular}{ccccccccccc}
\hline Units & U1 & U2 & U3 & U4 & U5 & U6 & U7 & U8 & U9 & U10 \\
\hline \multirow{2}{*}{ Results } & 19.91 & 19.74 & 19.74 & 19.18 & 19.64 & 19.66 & 19.44 & 19.57 & 19.74 & 19.74 \\
$(\mathrm{~g} / 10 \mathrm{~min})$ & 19.43 & 19.18 & 19.20 & 19.38 & 19.47 & 19.57 & 19.51 & 19.42 & 19.25 & 19.10 \\
& 19.41 & 19.60 & 19.54 & 19.74 & 19.59 & 19.42 & 19.57 & 19.39 & 19.43 & 19.60 \\
Mean & 19.58 & 19.51 & 19.49 & 19.43 & 19.57 & 19.55 & 19.51 & 19.46 & 19.47 & 19.48 \\
StDev & 0.29 & 0.29 & 0.27 & 0.29 & 0.09 & 0.12 & 0.06 & 0.10 & 0.24 & 0.34 \\
\hline
\end{tabular}

After PMTL-NIS measurements, five ISO 17025 accredited competent laboratories were selected to establish a network for confirmation of values assigned by NIS. Each laboratory received two samples and asked to measure three portions from each sample and provide nine repeatable measurement results; mean value and standard deviation of each collaborating laboratory are illustrated in Table 2 . The results were treated statistically for outliers, homogeneity of means, and variances. The ISO 5725:1-6 and ISO 13528 standards requirements were applied for estimation of assigned value and uncertainty. 
Characterization of low-density polyethylene reference material

Table 2. MFR test results for collaborating laboratories

\begin{tabular}{|c|c|c|c|c|c|c|c|c|c|c|}
\hline \multicolumn{11}{|c|}{ Participant Laboratories } \\
\hline & \multicolumn{2}{|c|}{ Lab1 } & \multicolumn{2}{|c|}{ Lab2 } & \multicolumn{2}{|c|}{ Lab3 } & \multicolumn{2}{|c|}{ Lab4 } & \multicolumn{2}{|c|}{ Lab5 } \\
\hline & S1 & $\mathbf{S 2}$ & S1 & S2 & S1 & S2 & S1 & S2 & S1 & $\mathbf{S 2}$ \\
\hline \multirow{9}{*}{ 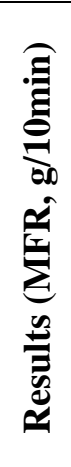 } & 20.45 & 20.77 & 19.45 & 19.77 & 19.64 & 19.44 & 19.21 & 19.40 & 18.97 & 19.05 \\
\hline & 20.47 & 20.86 & 19.47 & 19.86 & 19.47 & 19.51 & 19.42 & 19.15 & 18.94 & 19.02 \\
\hline & 20.55 & 20.76 & 19.55 & 19.76 & 19.59 & 19.57 & 19.47 & 19.34 & 18.96 & 19.01 \\
\hline & 20.72 & 20.64 & 19.72 & 19.64 & 19.18 & 19.91 & 19.72 & 19.63 & 18.94 & 18.91 \\
\hline & 20.76 & 20.60 & 19.76 & 19.60 & 19.38 & 19.43 & 19.64 & 19.75 & 19.01 & 18.96 \\
\hline & 20.77 & 20.62 & 19.77 & 19.62 & 19.39 & 19.41 & 19.52 & 19.36 & 18.97 & 18.94 \\
\hline & 20.57 & 20.49 & 19.57 & 19.49 & 19.74 & 19.57 & 19.19 & 19.52 & 18.94 & 19.04 \\
\hline & 20.68 & 20.75 & 19.68 & 19.75 & 19.25 & 19.54 & 19.53 & 19.48 & 18.94 & 19.00 \\
\hline & 20.65 & 20.63 & 19.65 & 19.63 & 19.43 & 19.39 & 19.38 & 19.72 & 18.91 & 19.02 \\
\hline
\end{tabular}

\subsection{Value Assignment}

The assigned value of the prepared reference material was calculated as the robust mean of results obtained by PMTL-NIS, the assigned value calculation was based on testing of about $10 \%$ of prepared units. The robust mean value and robust standard deviation of certification results were calculated statistically using algorithm A described in ISO 5725:1-6 [32] and ISO 13528 standards [33] and values were 19.51 and $0.197 \mathrm{~g} / 10 \mathrm{~min}$, respectively. Results obtained from collaborative study were analysed statistically and graphically using kernel density and box plots as illustrated in Figure 4 . The robust mean value of MFR calculated from collaborative study is $19.53 \mathrm{~g} / 10 \mathrm{~min}$. Also, same values were obtained from kernel density and box plot. This result is in a good agreement with homogeneity, stability and PMTL-NIS characterization results., this agreement confirms validity of preparation, measurements and value assignments.
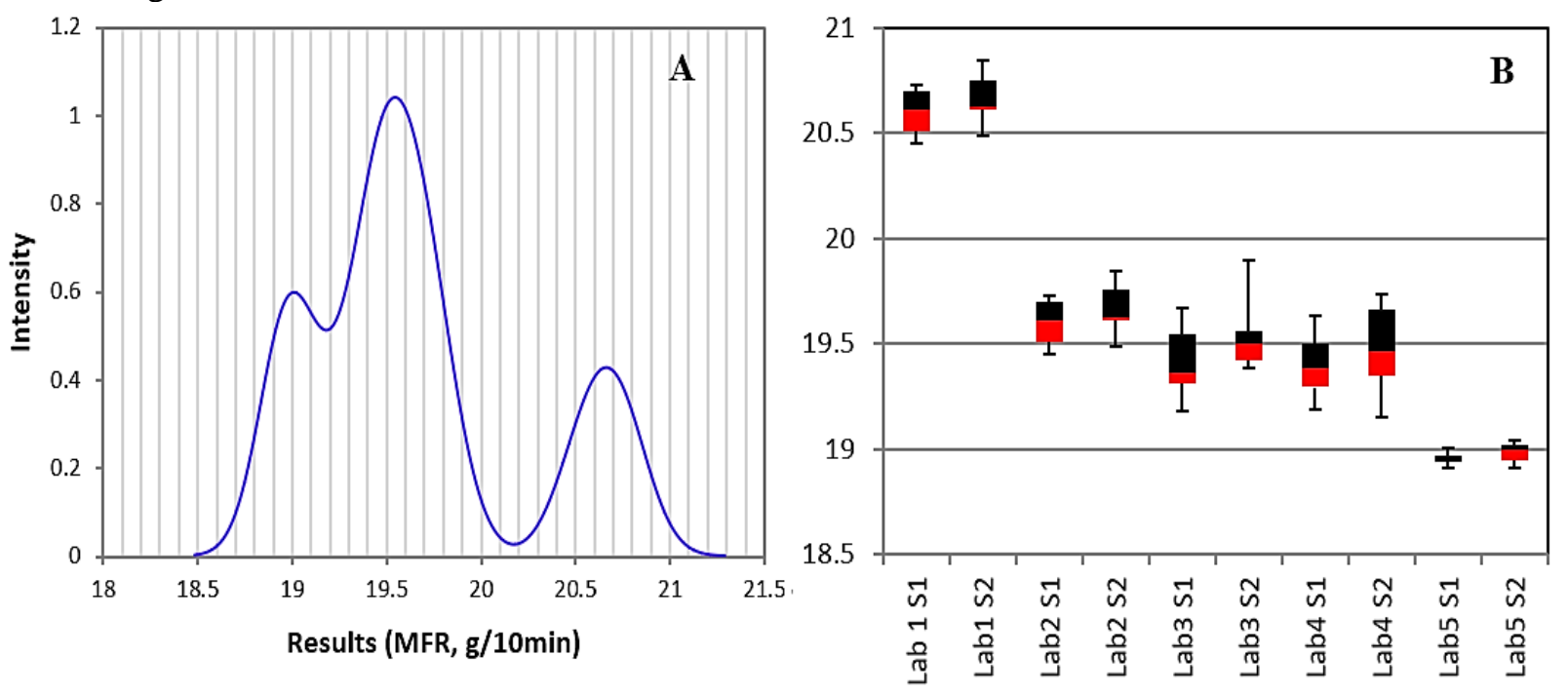

Figure 4. Statistical analysis of LDPE collaborative results: A) Kernel density plot and B) Box plot 


\subsection{Metrological Traceability and Measurement Uncertainty}

The traceability of the LDPE reference material to the definition of the SI units was achieved by the use of calibrated balance, stopwatch and plastometer, the measurements were traceable to the kilogram, second and kelvin SI base units. Estimated uncertainty was derived from the uncertainty components due to material heterogeneity $\left(u_{\mathrm{bb}}\right)$, short term and long-term stability $\left(u_{\mathrm{sts}}, u_{\mathrm{lts}}\right)$, characterization including uncertainties of time measurement, weighing, plastometer temperature, variability due to operators and plastometer as illustrated in Figure 5.

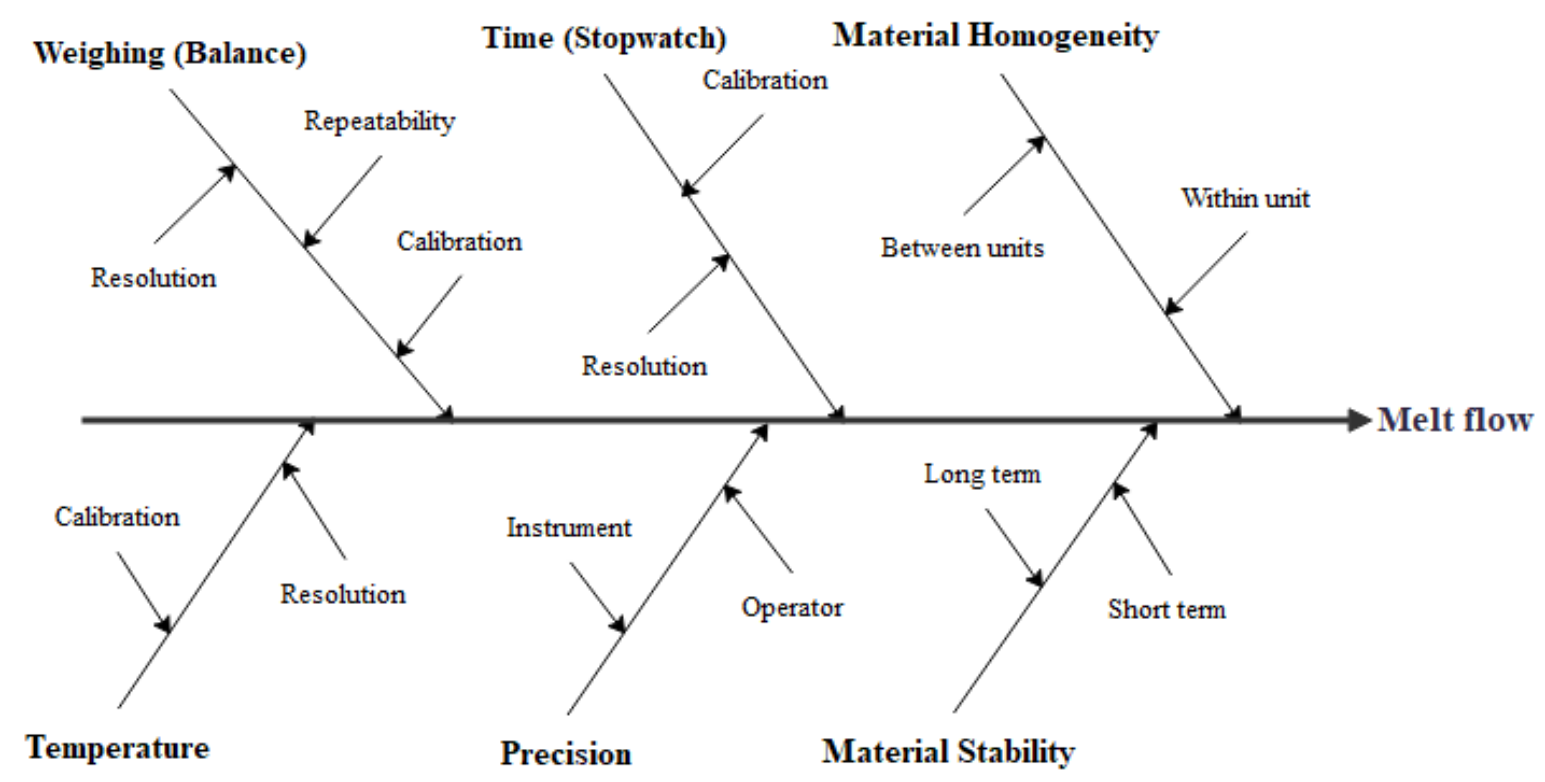

Figure 5. Fishbone diagram for uncertainty sources of LDPE reference material measurements

Expanded uncertainty is expressed as two times the root of the sum of the squares of standard uncertainties at a confidence level of approximately $95 \%$ [34,35], the values of uncertainties are illustrated in Table 3 .

\section{Conclusions}

This research was intended to prepare certified reference material based-MFR from LDPE pellets for using in calibration and performance assessment of equipment used in a variety of polymer laboratories and industries in Egypt and the MENA region. This test method was carried out according to ISO 1133-1 Standard. The homogeneity of the samples as well as the stability over 18 months were firstly assessed by NIS and then confirmed by a network of competent laboratories. The results were statistically analyzed to calculate the reference value. It was found to be $19.51 \mathrm{~g} / 10 \mathrm{~min}$. The value obtained from competent laboratories were investigated and then used to affirm PMTL-NIS data and found to be 19.53 $\mathrm{g} / 10 \mathrm{~min}$. The convergence between the two values was due to the good homogeneity and stability of the material. Moreover, there was no significant trend noticed over stability testing period. The certified value for LDPE and expanded uncertainty were concluded to be $19.51 \pm 0.38 \mathrm{~g} / 10 \mathrm{~min}$, according to detailed statistical analysis. This material will be beneficial for the calibration and quality control for the determination of the MFR using ISO 1133-1(procedure A) and can be used in testing laboratories and industrial quality control departments in different industrial sectors. 
Table 3. Uncertainty sources and their values used for estimation of uncertainty of reference material

\begin{tabular}{|c|c|c|c|c|c|c|c|}
\hline \multicolumn{2}{|c|}{ Source of uncertainty } & \multirow{2}{*}{$\begin{array}{c}\text { Estimated values } \\
0.007071068\end{array}$} & \multirow{2}{*}{$\begin{array}{c}\text { Unit } \\
\mathrm{g} / 10 \mathrm{~min}\end{array}$} & \multirow{2}{*}{$\begin{array}{c}\text { Distribution } \\
\text { Normal }\end{array}$} & \multirow{2}{*}{$\begin{array}{c}\text { Divisor } \\
1\end{array}$} & \multirow{2}{*}{$\begin{array}{c}\begin{array}{c}\text { Sensitivity } \\
\text { coefficient }\end{array} \\
1\end{array}$} & \multirow{2}{*}{$\begin{array}{c}\begin{array}{c}\text { Standard } \\
\text { uncertainty } \\
\text { (g/10 min) }\end{array} \\
0.007071\end{array}$} \\
\hline Repeatability of plastometer & Standard error & & & & & & \\
\hline Reproducibility of operators & Standard error & 0.058313499 & $\mathrm{~g} / 10 \mathrm{~min}$ & Normal & 1 & 1 & 0.058313 \\
\hline \multirow{2}{*}{ Weighting } & Calibration of Balance & 0.0003 & $\mathrm{~g}$ & Normal & 2 & 10 & 0.0015 \\
\hline & Resolution of Balance & 0.00005 & $\mathrm{~g}$ & Rectangle & 1.73 & 10 & 0.000289 \\
\hline \multirow{2}{*}{ Timing } & Calibration of stop watch & 0.00375 & $\mathrm{~s}$ & normal & 2 & -0.08317 & -0.00016 \\
\hline & Resolution of stop watch & 0.005 & $\mathrm{~s}$ & Rectangle & 1.73 & -0.08317 & -0.00024 \\
\hline \multirow{3}{*}{ Temperature } & $\begin{array}{l}\text { Calibration of } \\
\text { temperature }\end{array}$ & 0.2 & ${ }^{\circ} \mathrm{C}$ & Normal & 2 & 0.0385 & 0.00385 \\
\hline & Drift of temperature & -0.3 & ${ }^{\circ} \mathrm{C}$ & Rectangle & 1.73 & 0.0385 & -0.00667 \\
\hline & $\begin{array}{l}\text { Resolution of } \\
\text { temperature }\end{array}$ & 0.05 & ${ }^{\circ} \mathrm{C}$ & Rectangle & 1.73 & 0.0385 & 0.001111 \\
\hline Homogeneity & Material heterogeneity & 0.089 & $\mathrm{~g} / 10 \mathrm{~min}$ & Normal & 1 & 1 & 0.089 \\
\hline Stability & $\begin{array}{l}\text { Long- and short-term } \\
\text { stability }\end{array}$ & 0.16 & $\mathrm{~g} / 10 \mathrm{~min}$ & Normal & 1 & 1 & 0.16 \\
\hline \multicolumn{3}{|c|}{$\begin{array}{ll}\text { Combined standard uncertainty }(\mathrm{Uc}) & \text { stability }\end{array}$} & $\mathrm{g} / 10 \mathrm{~min}$ & \multirow{2}{*}{\multicolumn{3}{|c|}{$\mathrm{k}=2($ at $95 \%$ confidence level $)$}} & 0.19 \\
\hline \multicolumn{3}{|l|}{ Expanded uncertainty (Uc x 2) } & $\mathrm{g} / 10 \mathrm{~min}$ & & & & 0.38 \\
\hline
\end{tabular}




\section{Acknowledgements}

The authors are greatly acknowledged Gas and Polypropylene Lab at Egyptian propylene \& Polypropylene Co., Port Said-Egypt, MoharamPlast Quality Control Lab at MoharamPlast Co., Alexandria-Egypt, Red Sea Co. for Pipes Manufacturing \& Suppliers, $6^{\text {th }}$ of October, Giza-Egypt, Egyptian German Industrial Corporate (EGIC), $6^{\text {th }}$ of October, Giza-Egypt, and Composite Materials Lab at Central Metallurgical Research and Development Institute (CMRDI), Helwan-Egypt for collaboration in this study.

\section{Supporting Information}

Supporting information accompanies this paper on http://www.acgpubs.org/journal/ journalof-chemical-metrology

\section{ORCID}

Hesham Moustafa: 0000-0002-1034-8663

Ibrahim F. Tahoun: 0000-0002-0482-6198

Ahmed I. Abou-Kandil: 0000-0002-6231-6874

Nabila A. Darwish: 0000-0002-4535-7092

\section{References}

[1] H. P. Frank (1968). Polypropylene, Gordon and Breach Science Publishers, N.Y., pp.75.

[2] S. Matsuoka and T. K. Kwei (1979). Macromolecules, an introduction to polymer science, Ed. by F. A. Bovey and F. H. Winslow, Academic Press. N.Y., pp. 346.

[3] N. G. McCrum, C. P. Buckley and C. B. Bucknall (1988). Principles of polymer engineering, Oxford University Press, N.Y., pp. 279-280.

[4] J. L. Throne (1979). Plastics process engineering, Marcel Dekker, Inc., N.Y., pp. 239-247.

[5] J.R. Maurey, C.R. Schultheisz, W.R. Blair and C.M. Guttman (2002).Certification of standard reference material 1473b, low density polyethylene resin, Nat. Inst. Stand. Technol. Spec. Publ. Report No. $260-144$.

[6] T. Bremner, A. Rudin and D. G. Cook (1990). Melt flow index values and molecular weight distributions of commercial thermoplastics, J. Appl. Polym. Sci. 41, 1617-1627.

[7] A. Azmi, S. A. Sata, F. S. Rohman and N. Aziz (2019). Melt flow index of low-density polyethylene determination based on molecular weight and branching properties, J. Phys. Conf. Ser. 1349, 012094.

[8] ISO 1133 - 1 (2011). Plastics - Determination of the melt mass-flow rate (MFR) and melt volume flow rate (MVR) of thermoplastics - Part 1: Standard method.

[9] Development and use of reference materials and quality control materials, (2003). Vienna, IAEA-TECDOC1350 ISBN 92-0-103303-6 ISSN 1011-4289 @ IAEA, 2003 Printed by the IAEA in Austria.

[10] A. J. Peacock (2000). Handbook of polyethylene: structures, properties and applications. New York: CRC Press, Marcel Dekker, $1^{\text {st }}$ Edition.

[11] A. R. Adhikari, K. Lozano and M. Chipara (2011).Non-isothermal crystallization kinetics of polyethylene/carbon nanofiber composites, J. Compos. Mater. 46, 823-832.

[12] H. Moustafa, A. M. Karmalawi and A. M.Youssef (2021). Development of Dapsone-capped $\mathrm{TiO}_{2}$ hybrid nanocomposites and their effects on the UV radiation, mechanical, thermal properties and antibacterial activity of PVA bionanocomposites. Environ. Nanotechnol. Monit. Manag. 16, 100482.

[13] P. Gijsman (1994). The long-term stability of polyolefins, Eindhoven: Technische Universiteit Eindhoven.

[14] H. Moustafa, S.N. Lawandy, M. Rabee and M.A.H. Zahran (2020). Effect of green modification of nanoclay on the adhesion behavior of EPDM rubber to polyester fabric, Int. J. Adhes. Adhes. 100, 102617.

[15] E.A. Mwafy, A.A. Abd-Elmgeed, A.I. Abou-Kandil, M.M. Elfass and M.S. Gaafar (2015). High UV-shielding performance of zinc oxide/high-density polyethylene nanocomposites. Spectrosc. Lett. 48,646-652.

[16] A.I. Abou-Kandil, A. Awad and E. Mwafy (2015). Polymer nanocomposites part 2: Optimization of zinc oxide/high-density polyethylene nanocomposite for ultraviolet radiation shielding, J. Thermoplast. Compos. Mater. 28, 1583-1598. 
[17] F. Severini, R. Gallo, S. Ipsale and G. Ricca. (1993). Environmental degradation of LDPE observed by UV spectroscopy, Polym. Degrad. Stab. 41,103-107.

[18] A. A. El-Wakil, H. Moustafa and A. M. Youssef (2020). Antimicrobial low-density polyethylene/low-density polyethylene-grafted acrylic acid biocomposites based on rice bran with tea tree oil for food packaging applications, J. Thermoplast. Compos. Mater. 1-19. Doi: 10.1177/0892705720925140

[19] H. Moustafa, M. Morsy, M. A. Ateia and F. M. Abdel-Haleem (2021). Ultrafast response humidity sensors based on polyvinylchloride/graphene oxide nanocomposites for intelligent foodpackaging, Sens. Actuators A 331, 112918.

[20] Q.S.H. Chui, C. Franciscone, J.A.F. Baptista and D.S. Rosa (2007) An interlaboratory comparison of the melt flow index: relevant aspects for the participant laboratories, Polym. Test. 26, 576-586.

[21] ISO Guide 35 (2017) Reference materials - guidance for characterization and assessment of homogeneity and stability, International Organization for Standardization (ISO), Geneva.

[22] A.M.H. van der Veen, T.P.J. Linsinger, A. Lamberty and J. Pauwels (2001) Uncertainty calculations in the certification of reference materials 3. Stability study, Accred. Qual. Assur. 6, 257-263.

[23] ISO/IEC 17034 (2016) General requirements for the competence of reference material producers, International Organization for Standardization (ISO), Geneva.

[24] A.M.H. van der Veen, T. Linsinger and J. Pauwels (2001) Uncertainty calculations in the certification of reference materials.2. Homogeneity study, Accred. Qual. Assur. 6, 26-30.

[25] A.B. Shehata, M.S. Rizk, A.M. Farag, I.F. Tahoun (2014) Certification of three reference materials for $\alpha-$ and $\gamma$-tocopherol in edible oils, Mapan-J. Metrol. Soc. I. 29, 183-194.

[26] I.F. Tahoun and A.B. Shehata (2016) Preparation of honey reference material for water content by Karl Fisher and refractometric methods, Mapan-J. Metrol. Soc. I. 31, 25-29.

[27] I.F. Tahoun and A.B. Shehata (2016) Development of four parabens reference materials certified for purity mass fraction by mass balance approach, Mapan-J. Metrol. Soc. I. 31 145-152.

[28] T. P. J. Linsinger, J. Pauwels, A. M. H. van der Veen, H. Schimmel and A. Lamberty (2001) Homogeneity and stability of reference materials, Accred. Qual. Assur. 6, 20-25.

[29] I. F. Tahoun, R. N. Yamani and A. B. Shehata (2018) Preparation of quality control material for assuring quality of electrical conductivity measurements in soil, Egypt. J. Chem. 61 (4), 717 - 722.

[30] T.P.J. Linsinger, J. Pauwels, A. Lamberty, H.G. Schimmel, A.M.H. van der Veen and L. Siekmann (2001) Estimating the uncertainty of stability for matrix CRMs, Fresenius J. Anal. Chem .370, 183-188

[31] M. Ulberth-Buchgraber, M. Potalivo, H. Emteborg and A. Held (2011) Toward the Development of Certified Reference Materials for Effective Biodiesel Testing. Part 1: Processing, Homogeneity, and Stability. Energy Fuels 25, 4622-4629

[32] ISO 5725 : 1994 (1994) Accuracy (trueness and precision) of measurement methods and results, ISO, Geneva.

[33] ISO 13528:2015. Statistical methods for use in proficiency testing by interlaboratory comparison.

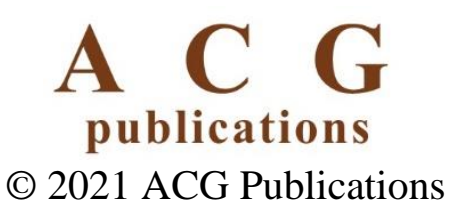

